\title{
Topical Cantharidine Solution
}

National Cancer Institute

\section{Source}

National Cancer Institute. Topical Cantharidine Solution. NCI Thesaurus. Code C163021.

A topical, diluted solution composed of the terpenoid cantharidin, which is a natural toxin extracted from blister beetles, that is dissolved in a film-forming vehicle, that can be used for its vesicant and keratolytic activities. Upon application of the topical cantharidine solution to the surface of the wart, the film dries and cantharidin is absorbed by the epidermal cells, thereby releasing serine proteases, and inducing acantholysis, thereby causing the disintegration and detachment of the desmosomes from the tonofilaments. This results in the formation of a small blister under the wart, which eventually falls off with the blistered skin. 